\title{
Communication \\ Mechanisms of Efficient Desalination by a Two-Dimensional Porous Nanosheet Prepared via Bottom-Up Assembly of Cucurbit[6]urils
}

\author{
Feng Zhou ${ }^{1, \dagger}$, Jaewoo Lee ${ }^{2,3, *,+(\mathbb{D})}$, Rong Wang ${ }^{4,5}$ and Haibin Su ${ }^{1, * \mathbb{D}}$ \\ 1 Department of Chemistry, The Hong Kong University of Science and Technology, Hong Kong 999077, China; \\ zhou0128.2012@gmail.com \\ 2 Department of Polymer-Nano Science and Technology, Jeonbuk National University, 567 Baekje-daero, \\ Deokjin-gu, Jeonju-si 54896, Korea \\ 3 Department of Bionanotechnology and Bioconvergence Engineering, Jeonbuk National University, \\ 567 Baekje-daero, Deokjin-gu, Jeonju-si 54896, Korea \\ 4 School of Civil and Environmental Engineering, Nanyang Technological University, \\ Singapore 639798, Singapore; rwang@ntu.edu.sg \\ 5 Singapore Membrane Technology Center, Nanyang Environment and Water Research Institute, \\ Nanyang Technological University, Singapore 637141, Singapore \\ * Correspondence: jaewoolee@jbnu.ac.kr (J.L.); haibinsu@ust.hk (H.S.) \\ + These authors contributed equally to this work.
}

check for updates

Citation: Zhou, F.; Lee, J.; Wang, R.; $\mathrm{Su}, \mathrm{H}$. Mechanisms of Efficient Desalination by a Two-Dimensional Porous Nanosheet Prepared via Bottom-Up Assembly of Cucurbit[6]urils. Membranes 2022, 12, 252. https://doi.org/10.3390/ membranes12030252

Academic Editor: Alessandra Criscuoli

Received: 27 January 2022

Accepted: 21 February 2022

Published: 23 February 2022

Publisher's Note: MDPI stays neutral with regard to jurisdictional claims in published maps and institutional affiliations.

Copyright: (C) 2022 by the authors. Licensee MDPI, Basel, Switzerland. This article is an open access article distributed under the terms and conditions of the Creative Commons Attribution (CC BY) license (https:// creativecommons.org/licenses/by/ $4.0 /)$.

\begin{abstract}
Many researchers have examined the desalination performance of various kinds of twodimensional (2D) porous nanosheets prepared by top-down approaches such as forming pores on the plain based on molecular dynamics (MD) simulations. In contrast, it is rare to find MD simulations addressing the desalination performance of a 2D porous nanosheet prepared by bottomup approaches. We investigated the desalination performance of a 2D porous nanosheet prepared by the assembly of cucurbit[6]uril (CB[6]) via MD simulation. The model 2D CB[6] nanosheet features $\mathrm{CB}[6]$ with the carbonyl-fringed portals of $3.9 \AA$ and the interstitial space filled with hydrophobic linkers and dangling side chains. Our MD simulation demonstrated that the 2D porous $\mathrm{CB}[6]$ nanosheet possesses a 70 to 140 times higher water permeance than commercial reverse osmosis membranes while effectively preventing salt passage. The extremely high water permeance and perfect salt rejection stem from not only $\mathrm{CB}[6]$ 's nature (hydrophilicity, negative charge, and the right dimension for size exclusion) but also the hydrophobic and tightly filled interstitial space. We also double-checked that the extremely high water permeance was attributable to only CB[6]'s nature, not water leakage, by contrasting it with a 2D nanosheet comprising CB[6]-spermine complexes. Lastly, this paper provides a discussion on a better cucurbituril homologue to prepare a next-generation desalination membrane possessing great potential to such an extent to surpass the 2D porous $\mathrm{CB}[6]$ nanosheet based on quantum mechanics calculations.
\end{abstract}

Keywords: two-dimensional material; cucurbituril; desalination; molecular dynamics simulation; quantum mechanics calculation

\section{Introduction}

Two-dimensional (2D) nanomaterials such as graphene oxide or MXenes have received much attention as a compelling alternative for membrane fabrication owing to their unique properties capable of inducing low frictional water flow through the interlayer spacing (or d-spacing) in recent years [1,2]. However, the use of 2D nanomaterials has been restricted mainly to ultrafiltration or molecular separation (i.e., nanofiltration) in many cases due to their larger permeation cutoff than hydrated ions $[1,3,4]$. For this reason, even the best graphene laminates for desalination have exhibited a much lower performance than in-house polymeric RO membranes (e.g., 4.68-5.54 $\mathrm{L} \mathrm{m}^{-2} \mathrm{~h}^{-1} \mathrm{bar}^{-1}$ with 98.2-98.9\% 
$\mathrm{NaCl}$ rejection in $\mathrm{RO}$ using a $2000 \mathrm{NaCl}$ feed solution [5-8]), although their water permeance was almost 10 times lower than in-house ones. For example, the GO laminate membrane made by spray coating an aqueous solution containing $\mathrm{GO}$ and few-layered graphene/deoxycholate exhibited $0.46 \mathrm{~L} \cdot \mathrm{m}^{-2} \cdot \mathrm{h}^{-1} \cdot \mathrm{Bar}^{-1}$ with $85 \% \mathrm{NaCl}$ rejection in $\mathrm{RO}$ using a $2000 \mathrm{NaCl}$ feed solution [9]. As another example, the laminate membrane consisting of chemically converted graphene using tannic acid showed $0.36 \mathrm{~L} \mathrm{~m}^{-2} \mathrm{~h}^{-1} \mathrm{bar}^{-1}$ with $80-92 \% \mathrm{NaCl}$ rejection in $\mathrm{RO}$ using a $500-2000 \mathrm{NaCl}$ feed solution [10]. These results imply that the d-spacing of laminate membranes is too large to separate monovalent ions and too tortuous to allow fast water transport as compared to polymeric $\mathrm{RO}$ membranes. As a result, laminate membranes are still too far from practical application in seawater desalination.

In contrast to the laminates, porous nanosheets with sub-nanometer pores have been regarded as the ultimate form to realize the ideal selectivity and outstanding water permeability simultaneously, which was supported by a few simulation studies [11-14]. For instance, a single-layer graphene nanosheet showed several orders of magnitude higher water permeability than the existing $\mathrm{RO}$ membranes while separating ions adequately during MD simulations [11]. Furthermore, the possibility of improving the desalination performance of porous single-layer nanosheets has been reported consistently through MD simulations accompanied by the modification of pore designs or desalination conditions up to recently [15-17]. Such porous nanosheets are likely to be fabricated by means of state-of-the-art technologies such as direct focused ion beam (FIB) drilling [18]. However, in reality it is challenging to prepare finely perforated $2 \mathrm{D}$ nanomaterial-based membranes with pores small enough to reject ion species with the currently available technologies. To the best of our knowledge, the smallest aperture size that can be formed by direct FIB drilling is about $3 \mathrm{~nm}$ [19], which is too large to separate ions from seawater. All things considered, a bottom-up approach could be a more realistic way, as of now, to prepare feasible 2D nanomaterial-based membranes for desalination.

In a bottom-up manner to develop more permeable and selective membranes, it is of importance to carefully choose novel materials for selective water transport over ions. In this context, one needs to note the possibility of designing synthetic water channels as building blocks based on the biological structures or self-assembly of supra-molecules and utilizing them to offer great advantages in terms of the permselectivity of desalination membranes [20-22]. Among several synthetic water channels, cucurbituril homologues, which are macrocycles with sub-nanometer pores [23-25], can be considered as a promising candidate for selective water transport owing to its well-defined channel structure and carbonyl-fringed portal. However, this material has not yet been explored as a single-layer membrane in spite of its great potential. For example, Baek et al. prepared laminate membranes consisting of 2D cucurbit[6]uril (CB[6]) nanosheets for molecular separation after filling $\mathrm{CB}[6]$ 's cavity with guest molecules to fully delaminate the 2D nanosheets [26]. However, their membrane was far from a single-layer membrane with desirable pores for selective water transport due to the preparation method (i.e., laminate membranes and cavities filled with guest molecules). Meanwhile, Cao et al. [27] and Lee et al. [28] have recently demonstrated the great potential of $\mathrm{CB}[6]$ for selective water transport in the form of polymeric nanocomposite membranes, but their membranes were also inappropriate for exploring the performance of a single-layer $\mathrm{CB}[6]$ membrane.

In this study, we carried out molecular dynamics (MD) simulations to estimate the desalination performance of a 2D porous nanosheet assembled with $\mathrm{CB}[6] \mathrm{s}$. A model $2 \mathrm{D}$ porous $\mathrm{CB}[6]$ nanosheet was assembled by referring to the structure reported in the previous study [29] except for filling the cavity with a guest molecule. Our MD simulations revealed that the model porous nanosheet possesses great potential as a next-generation desalination membrane by showing superfast water transport and perfect salt rejection. Additionally, we double-checked that the extremely high water permeance of the 2D CB[6] nanosheet does not result from leakage but CB[6]'s nature. This fact was evidenced by contrasting it with a 2D nanosheet consisting of host-guest complexes (i.e., cavities filled with guest molecules). Lastly, quantum mechanics (QM) calculations were performed 
to predict the best candidate among cucurbituril homologues to construct a single-layer porous nanosheet for desalination.

\section{Molecular Dynamics (MD) Simulation and Quantum Mechanics (QM) Calculation}

All simulations were carried out using the GROMACS 4.5.3 suite of programs [30]. The CB[6] and water molecules were described using the amber03 force field [31] and the tip5p water model [32], respectively. All simulations were conducted under periodic boundary conditions at constant temperature and pressure (NPT). The initial coordinates of the small molecules were made from Gaussview [33]. The SPC/E, PPC, and TIP4P [34], and BSV, CC, DC, SPC/E, and TIP4P [35] models were reported as failing to adequately represent the experimental $\mathrm{O} \cdots \mathrm{O}$ radial distribution function. The TIP3P and SPC exhibit particularly poor agreement, while the TIP4P, SPC/E, and PPC show better agreement. However, the recent models TIP4P-FQ and increasingly used TIP5P [32] provide further improvement [36] at a higher computational cost. In this paper, we used TIP5P to model water for MD simulation studies.

As for QM calculations, all species used in the energy scan regarding hydrated sodium ions approaching the cavity center were entirely optimized by the density functional theory (DFT) at the M06-2X/6-31g(d) level [37,38]. All computations were performed with Gaussian 09 package [39]. The convergence thresholds were set as follows: $10^{-3}$ a.u. for the gradient, $10^{-3}$ a.u. for the displacement, and $10^{-6}$ a.u. for the energy, respectively. We utilized the polarizable continuum model (PCM) to model the water environment for the QM calculation.

\section{Results and Discussion}

3.1. MD Simulations to Determine the Desalination Performance of the $2 D$ Porous CB[6] Nanosheet

The previous study demonstrated that $\mathrm{CB}[6]$ can be used to improve the permselectivity of thin-film nanocomposite reverse osmosis membranes thanks to the selective water transport characteristics of $\mathrm{CB}$ [6] [28]. However, the ideal future scenario would be to construct a single-layer film by seamlessly assembling CB[6]s on top of a porous support to make full use of $\mathrm{CB}[6]$ 's performance. Thus, we carried out MD simulations using the GROMACS 4.5.3 package [30] to predict the desalination performance of a 2 D porous $C B$ [6] nanosheet. A $2 \times 2$ supercell was used to realize an infinite 2D CB[6] nanosheet (Figures 1 and 2), which comprises four $\mathrm{CB}$ [6] units, the thioether bridges to link the neighboring $\mathrm{CB}[6]$ units, $-\mathrm{O}\left(\mathrm{CH}_{2}\right)_{3}-\mathrm{S}\left(\mathrm{CH}_{2}\right)_{2} \mathrm{~S}-\left(\mathrm{CH}_{2}\right)_{3} \mathrm{O}-$, and the dangling side chains $-\mathrm{O}\left(\mathrm{CH}_{2}\right)_{3}-\mathrm{S}\left(\mathrm{CH}_{2}\right)_{2} \mathrm{~S}-\left(\mathrm{CH}_{2}\right)_{2} \mathrm{OCH}_{2} \mathrm{CH}_{3}$, filling the interstitial space between $\mathrm{CB}[6]$ units, as reported previously [29]. The initial system configuration was subject to periodic boundary conditions and consisted of a box measuring approximately $39 \AA(\mathrm{x}) \times 39 \AA(\mathrm{y}) \times 102 \AA(\mathrm{z})$. We placed 1409 water molecules on the saltwater side along with $60 \mathrm{NaCl}$ ions, and 1465 water molecules were placed on the freshwater side. The salt water had a concentration of $2.37 \mathrm{M}$, which has an osmotic pressure of $115 \mathrm{bar}$. In our simulation, the osmotic pressure drives water molecules to transport across the CB[6] nanosheet. Thus, the high concentrated salt water was used to simulate a higher applied pressure than the osmotic pressure of seawater of about $0.6 \mathrm{M}$, and the water permeability coefficient is evaluated by dividing the water flux by the osmotic pressure. 
(a)

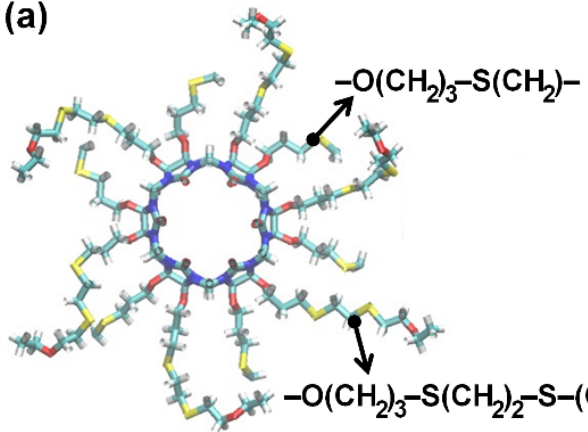

(c)

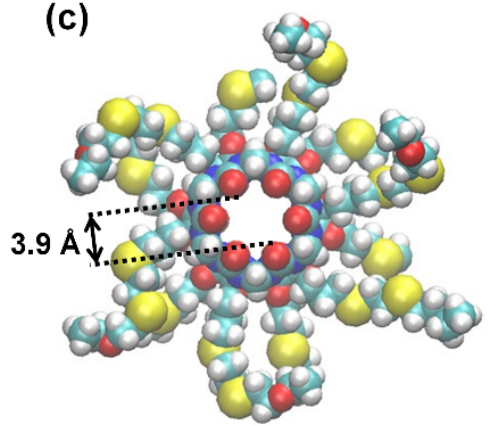

(b)

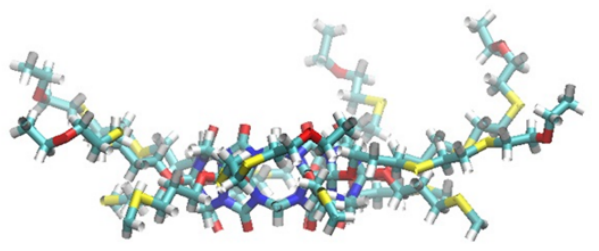

Figure 1. Top $(\mathbf{a}, \mathbf{c})$ and side $(\mathbf{b}, \mathbf{d})$ views of the modified $\mathrm{CB}[6]$ with six thioether bridges $\left(-\mathrm{O}\left(\mathrm{CH}_{2}\right)_{3}-\mathrm{S}\left(\mathrm{CH}_{2}\right)-\right)$ and dangling arms $\left(-\mathrm{O}\left(\mathrm{CH}_{2}\right)_{3}-\mathrm{S}\left(\mathrm{CH}_{2}\right)_{2} \mathrm{~S}-\left(\mathrm{CH}_{2}\right)_{2} \mathrm{OCH}_{2} \mathrm{CH}_{3}\right)$. $-\mathrm{O}\left(\mathrm{CH}_{2}\right)_{3}-\mathrm{S}\left(\mathrm{CH}_{2}\right)-$ corresponds to a symmetric half of the linker. $(\mathbf{a}, \mathbf{b})$ do not include van der Waals spheres, whereas (c,d) do. Color scheme: N, blue; C, cyan; $\mathrm{O}$, red; $\mathrm{H}$, white; $\mathrm{S}$, yellow.

(a)

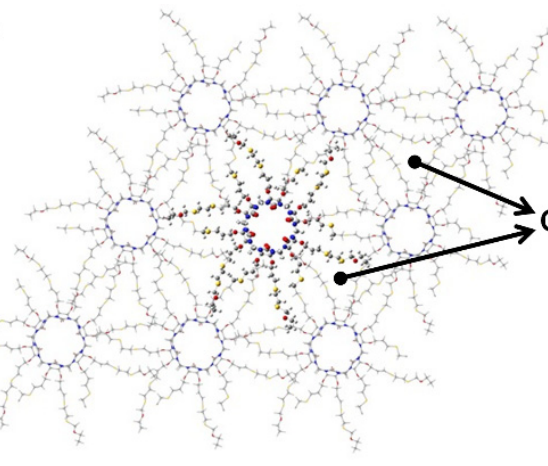

(c)

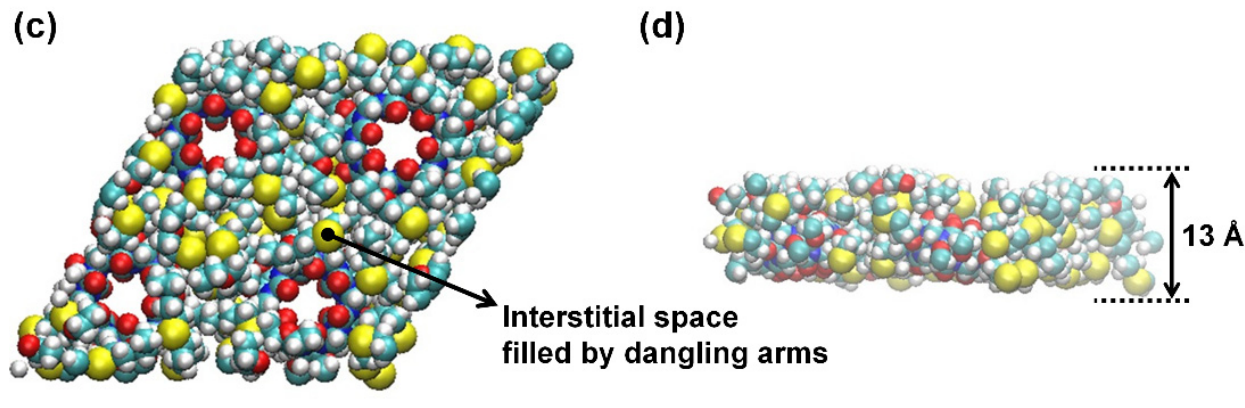

(b)

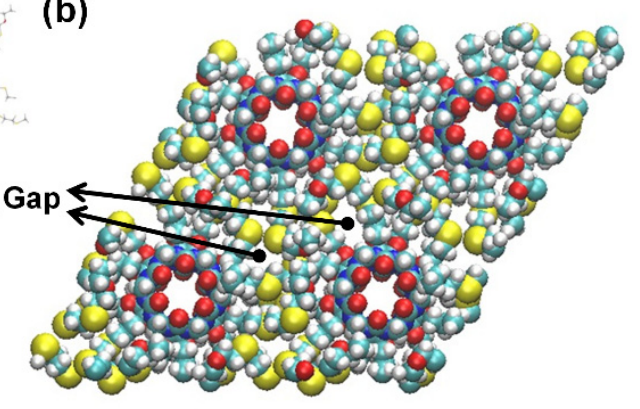

(d)

Figure 2. Top view of the $2 \mathrm{D} \mathrm{CB}[6]$ nanosheet with (a) sticks and (b) spheres models at 0 ns. (c) Top view and (d) side view of the 2D CB[6] nanosheet at $10 \mathrm{~ns}$. The gaps between the neighboring CB[6] units observed at $0 \mathrm{~ns}$ were determined to be filled by the dangling arms, which were intended to form a thicker and denser hydrophobic region. Once the dangling arms agglomerated to fill the empty interstitial space, the hydrophobic region (about $13 \AA$ ) became thicker than the height $(9.1 \AA$ ) of $\mathrm{CB}[6]$. Color scheme: N, blue; $\mathrm{C}$, cyan; O, red; H, white; S, yellow. 
Figure $3 a, b$ illustrate the setup of our simulation on the water flow across the 2D CB[6] nanosheet. During the 100 ns simulation, 350 water molecules migrated across the 2D $\mathrm{CB}[6]$ nanosheet. The water transport rate was calculated to be $7.6 \times 10^{6}$ water molecules unit $^{-1} \mathrm{sec}^{-1} \mathrm{bar}^{-1}$, translating into $212 \mathrm{~L} \mathrm{~m}^{-2} \mathrm{~h}^{-1} \mathrm{bar}^{-1}$. This intrinsic water permeability is about 70 to 140 times higher than commercial RO membranes. More importantly, such excellent water permeability was achieved without any salt passage. $\mathrm{NaCl}$ ions can hardly diffuse through not only the $\mathrm{CB}$ [6] portal due to the remarkable electrostatic repulsion [28] but also the inter-CB[6] space because of the hydrophobic nature of the linker and the effective space filled by side chains. The dynamic behavior of water molecules in the $\mathrm{CB}[6]$ nanosheet is presented in Figure 3c, which demonstrates that water molecules are predominantly passing through the $\mathrm{CB}[6]$ cavity instead of the hydrophobic interstitial space. To be specific, water molecules randomly distributed at $0 \mathrm{~ns}$ were arranged and then migrated along four CB[6] channels (red arrow) at $100 \mathrm{~ns}$. This implies that water molecules mostly permeate through the $\mathrm{CB}[6]$ cavity, whereas the hydrophobic interstitial space is not preferred for water permeation when the $\mathrm{CB}[6]$ portal is open.

(a)
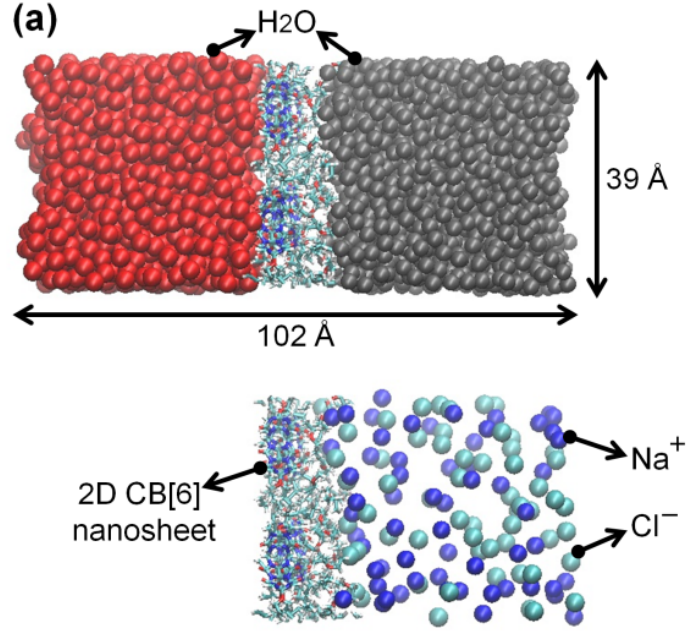

(c)

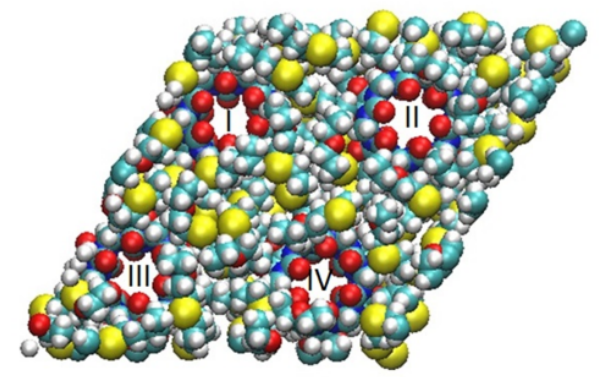

(b)
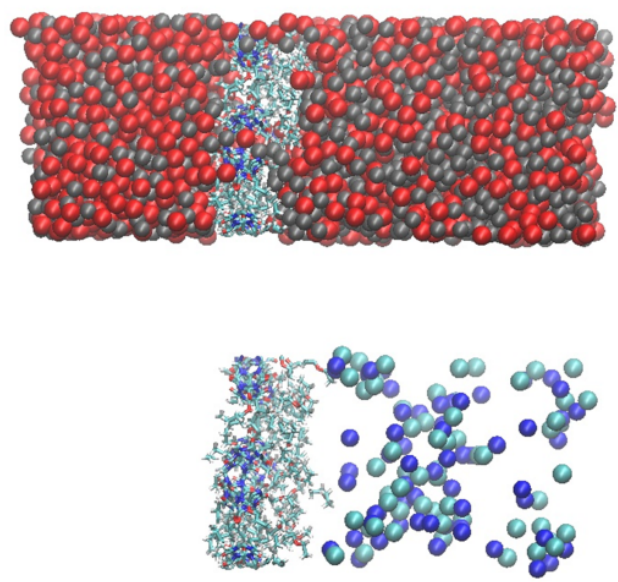

Figure 3. Simulation system consists of the 2D CB[6] nanosheet, pure water (red sphere, left), and a $2.37 \mathrm{M} \mathrm{NaCl}$ solution (gray sphere, right) at (a) 0 and (b) $100 \mathrm{~ns}$. Water molecules and $\mathrm{NaCl}$ ions of salt water are presented separately for clarity. (c) Top view of the 2D CB[6] nanosheet (left) and side view of the simulation system including water molecules within $5 \AA$ away from the 2D CB[6] nanosheet at $100 \mathrm{~ns}$ (right).

\subsection{Investigation of the Possibility of Water Leakage through the Interstitial Space}

We also attempted to determine whether the high water permeance of the 2D CB[6] nanosheet results from $\mathrm{CB}[6]$ 's features, not leakage through the inter-CB[6] space. To test the possibility of water leakage, we prepared another $2 \mathrm{D}$ nanosheet by replacing four $\mathrm{CB}[6]$ units with four $\mathrm{CB}[6]$-spermine complexes. According to the previous study [28], the hostguest complex consisting of $\mathrm{CB}[6]$ and fully protonated spermine was identified to have a much higher binding energy $\left(-231.9 \mathrm{kcal} \mathrm{mol}^{-1}\right)$ than $\mathrm{CB}[6] \cdot \mathrm{H} 2 \mathrm{O}\left(-14.02 \mathrm{kcal} \mathrm{mol}^{-1}\right)$. 
This fact suggests that water molecules cannot replace the bound spermine and thereby permeate through the $\mathrm{CB}[6]$-spermine complex from the point of view of energetics. Accordingly, if a significant net flow of water is observed in the MD simulation using the 2D $\mathrm{CB}[6]$-spermine nanosheet, it indicates water leakage through the inter-CB[6] space. Additionally, the degree of water leakage helps us where the extremely high water permeance comes between $\mathrm{CB}[6]$ 's nature and the water leakage.

To clarify where the extremely high water permeance of the $2 \mathrm{D}$ porous $\mathrm{CB}$ [6] nanosheet comes from, we carried out a $100 \mathrm{~ns}$ MD simulation using the 2D CB[6]-spermine nanosheet. A $2 \times 2$ supercell was used to realize the infinite 2D CB[6]-spermine nanosheet, which consists of four $\mathrm{CB}[6]$-spermine complexes, the thioether bridges to link the neighboring $\mathrm{CB}[6]$-spermine complexes, $-\mathrm{O}\left(\mathrm{CH}_{2}\right)_{3}-\mathrm{S}\left(\mathrm{CH}_{2}\right)_{2} \mathrm{~S}-\left(\mathrm{CH}_{2}\right)_{3} \mathrm{O}-$, and the dangling side chains, $-\mathrm{O}\left(\mathrm{CH}_{2}\right)_{3}-\mathrm{S}\left(\mathrm{CH}_{2}\right)_{2} \mathrm{~S}-\left(\mathrm{CH}_{2}\right)_{2} \mathrm{OCH}_{2} \mathrm{CH}_{3}$, filling the interstitial space between $\mathrm{CB}[6]$-spermine complexes. The initial system configuration was subject to periodic boundary conditions and consisted of a box measuring approximately $39 \AA(x) \times 39 \AA(y) \times 126 \AA(z)$. We used 2880 water molecules for both the fresh and salt water; 44 sodium and 60 chloride ions were placed on the saltwater side.

The MD simulation shows that no water molecules passed through the $C B[6]$-spermine complex as expected. Meanwhile, only three water molecules crossed the interstitial space for 100 ns, as shown in Figure 4 and Figure S1. In detail, two water molecules (red spheres) crossed from the fresh water to the salt water, while one water molecule (grey sphere) crossed from the salt water to the fresh water. This result means that the $2 \mathrm{D} \mathrm{CB}[6]$-spermine nanosheet reveals the net flow of water corresponding to only one water molecule. The net flow of water through the 2D CB[6]-spermine nanosheet is negligible, even allowing for the fact that the $\mathrm{CB}[6]$ cavities were blocked, considering that it was 350 water molecules in the case of the 2D porous $\mathrm{CB}[6]$ nanosheet. Accordingly, it is clear from this discussion that the extremely high water permeance of the $2 \mathrm{D}$ porous $\mathrm{CB}[6]$ nanosheet stems from $\mathrm{CB}[6]$ 's nature.

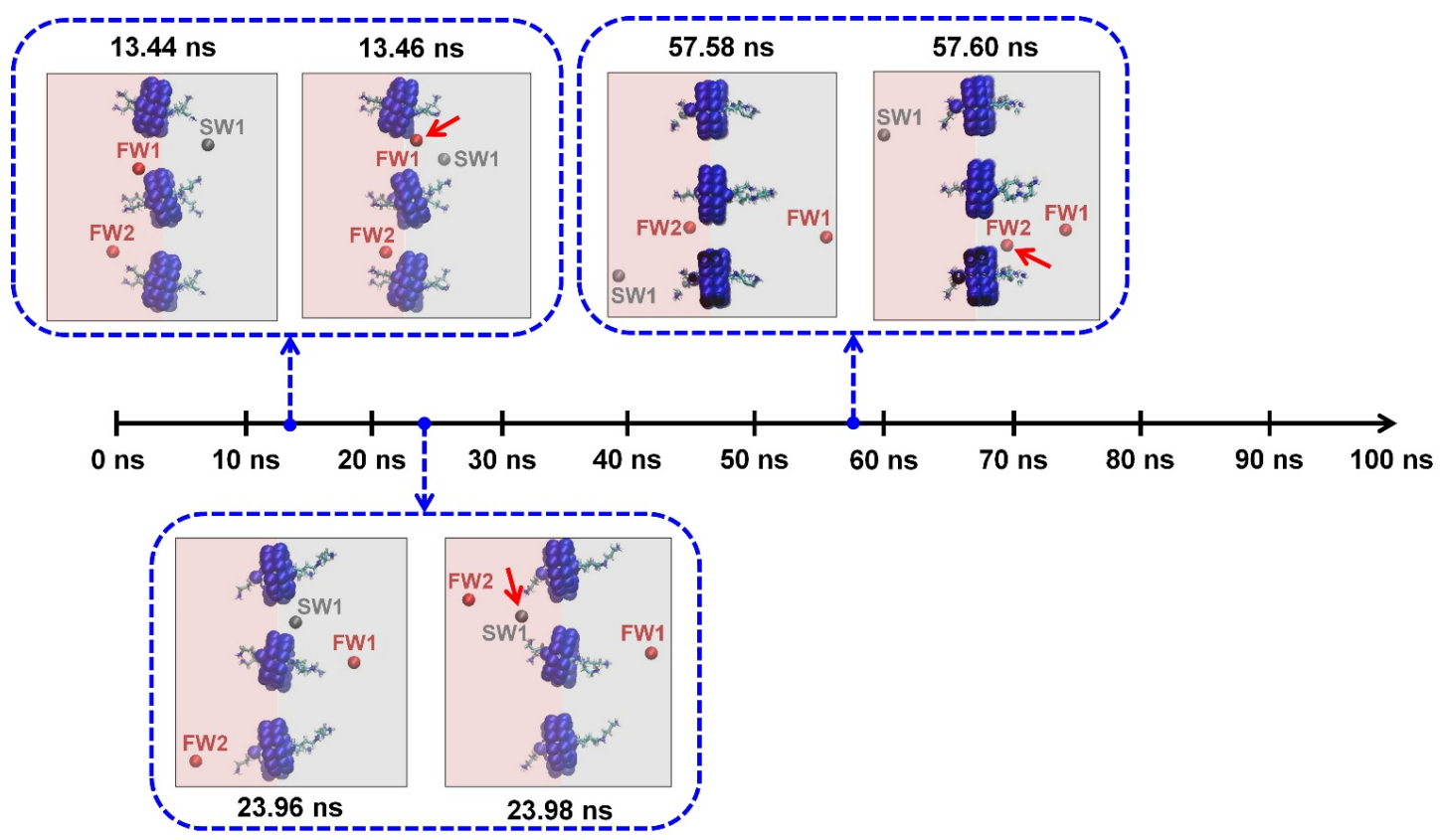

Figure 4. Six frames show water passage across the interstitial space of the 2D CB[6]-spermine nanosheet for $100 \mathrm{~ns}$. The frames represent the three water molecules moving across the interstitial space. The FW1 and FW2 signify two water molecules on the freshwater side, while the SW1 means a water molecule on the saltwater side. The red and grey highlights present the freshwater and saltwater side, respectively. The red arrows indicate the water molecules that moved to the other side. Meanwhile, thioether bridges, dangling arms, $\mathrm{NaCl}$ ions, and the other water molecules on the freshwater (red, left) and saltwater (gray, right) sides are not shown for clarity. 


\subsection{QM Calculations to Weigh Up the Best Candidate among Cucurbituril Homologues}

The previous study demonstrated that $\mathrm{CB}[6]$ possesses selective water transport characteristics stemming from the carbonyl-fringed portal of $3.9 \AA$ [28]. However, it does not necessarily mean that $\mathrm{CB}[6]$ is the best among cucurbituril homologues to make desalination membranes. Accordingly, we tried to determine which is better between $\mathrm{CB}[6]$ and $\mathrm{CB}[7]$ as a building block for desalination membranes. $\mathrm{CB}[5]$ and $\mathrm{CB}[8]$ were excluded from consideration because $\mathrm{CB}[5]$ has a smaller portal (2.4 $\AA$ [25]) than water molecule $(2.75 \AA)$, while $\mathrm{CB}[8]$ has a larger portal (6.9 $\AA$ [25]) than a hydrated chloride ion $(6.6 \AA)$. First, we compared the binding energies between one water molecule and the two cucurbituril homologues to weigh up which one is more desirable to afford fast water transport. Here, a lower binding energy equals faster water transport through cucurbituril homologues. $\mathrm{CB}[6] \cdot \mathrm{H}_{2} \mathrm{O}$ and $\mathrm{CB}[7] \cdot \mathrm{H}_{2} \mathrm{O}$ (Figure S2) showed the binding energies of -14.9 and $-1.27 \mathrm{kcal} \mathrm{mol}^{-1}$, respectively. This result implies that $\mathrm{CB}$ [7] can be more favorable than $\mathrm{CB}[6]$ for fast water transport through the cavity owing to the lower binding energy.

However, too large of a portal can backfire from the perspective of preventing salt passage. With this in mind, we performed QM calculations using CB[6], CB[7], and a hydrated sodium ion. According to our calculations, as a hydrated sodium ion approached the center of the $\mathrm{CB}[6]$ and $\mathrm{CB}[7]$ cavities, the relative energies increased by 22.3 and $12.4 \mathrm{kcal} \mathrm{mol}^{-1}$, respectively (Figure 5). The increased relative energies are assumed to be associated with geometrical deformation that a hydrated sodium ion would go through in the cavity, as reported previously [28]. More importantly, CB[7] also exhibits a certain level of energy barrier imposed by the cavity while a hydrated sodium ion approaches the cavity center, which suggests that $\mathrm{CB}[7]$ is also likely to prevent salt passage. Overall, it is worth trying to examine whether $\mathrm{CB}$ [7] is a more desirable building block to prepare a 2D porous nanosheet for desalination in that it could promote fast water transport due to the low binding energy of $\mathrm{CB}[7] \cdot \mathrm{H}_{2} \mathrm{O}$ while inhibiting salt passage because of the energy barrier imposed by the $\mathrm{CB}[7]$ cavity.

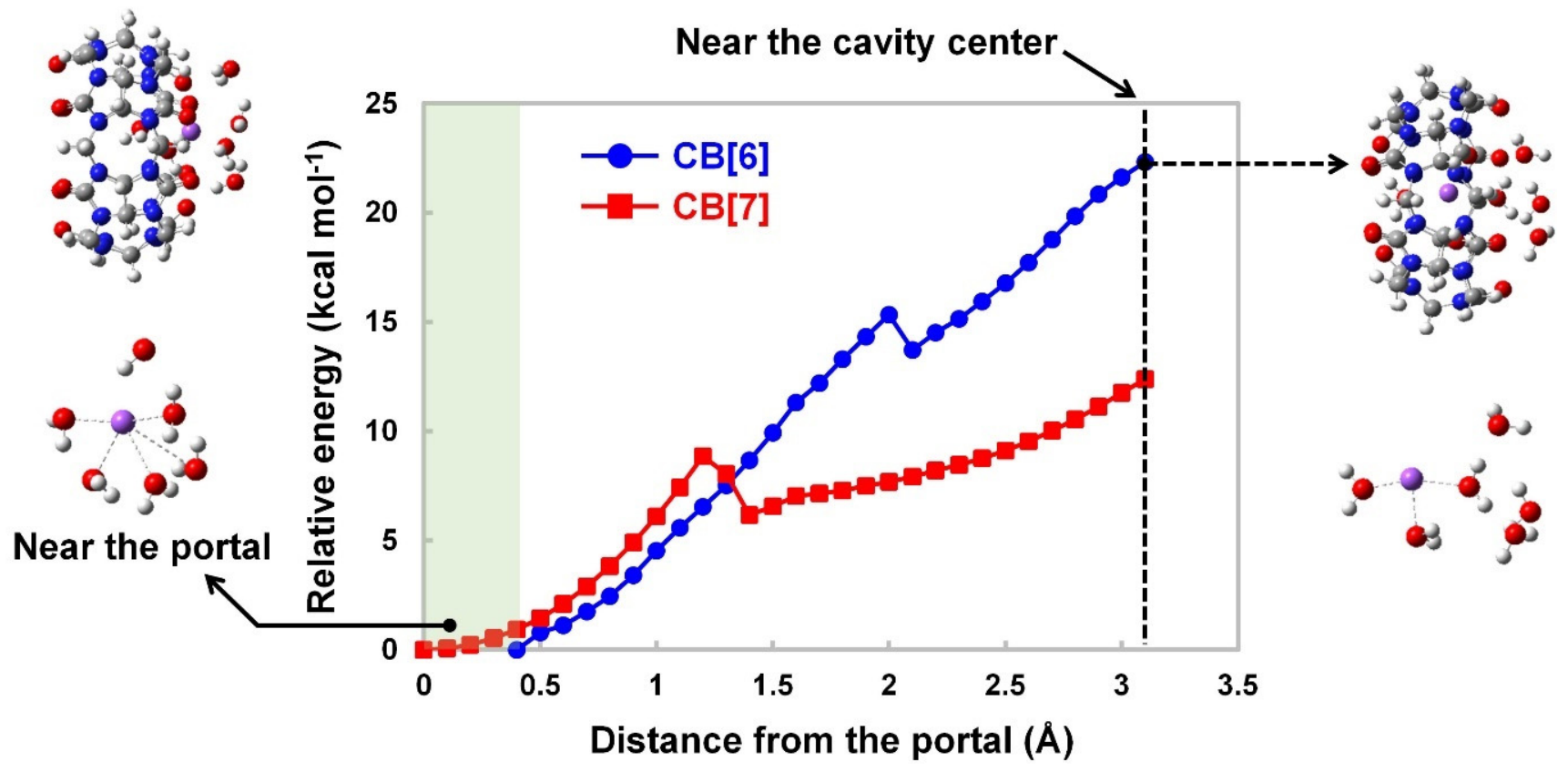

Figure 5. The $\mathrm{CB}[6]$-ion and $\mathrm{CB}[7]$-ion complexes' relative energies as a function of the distance between a hydrated sodium ion and the portal. The first water shell was used to calculate the energy barrier of a hydrated sodium ion. The molecular structure of a hydrated sodium ion outside CB[6] was described on the left side, while the right illustration shows the structure in the center of the cavity (color scheme: $\mathrm{C}$, grey; $\mathrm{N}$, blue; $\mathrm{H}$, white; $\mathrm{O}$, red; $\mathrm{Na}$, purple). 


\section{Conclusions}

Our simulation revealed that a single layer of the defect-free $2 \mathrm{D}$ porous $\mathrm{CB}[6]$ nanosheet is likely to produce fresh water at a rate that is two orders of magnitude faster than commercial reverse osmosis membranes while retaining ions. The extremely high water permeance was found to arise from the carbonyl-fringed portal of $3.9 \AA$, which was double-checked by negligible water leakage even through the interstitial space between $C B[6]$-spermine complexes. Lastly, the potential of $\mathrm{CB}$ [7] as a building block for desalination membranes was also identified by the low binding energy of $\mathrm{CB}$ [7] $\cdot \mathrm{H}_{2} \mathrm{O}$ and the energy barrier imposed by the CB[7] cavity. We expect that this study can play a catalytic role in the development of 2D porous nanosheet for desalination through bottom-up assembly.

Supplementary Materials: The following are available online at https:/ / www.mdpi.com/article/ 10.3390 / membranes12030252/s1, Figure S1: simulation system consisting of the 2D nanosheet with four $\mathrm{CB}[6]$-spermine complexes, Figure S2: optimized structures of $\mathrm{CB}[6]$ and $\mathrm{CB}[7]$ with one water molecule.

Author Contributions: Conceptualization, H.S.; methodology, F.Z.; software, F.Z.; validation, F.Z. and J.L.; formal analysis, F.Z. and J.L.; investigation, F.Z. and J.L.; resources, H.S. and R.W.; data curation, F.Z. and J.L.; writing—original draft preparation, F.Z. and J.L.; writing—review and editing, J.L. and H.S.; visualization, F.Z. and J.L.; supervision, H.S. and R.W.; project administration, H.S. and R.W.; funding acquisition, H.S. and R.W. All authors have read and agreed to the published version of the manuscript.

Funding: This work was supported by the Singapore National Research Foundation under its Environmental \& Water Industry Programme (grant number: 1501-IRIS-04) and administered by PUB, Singapore's National Water Agency. This research was also supported by HKUST grant (grant number: R9418) and Basic Science Research Program through the National Research Foundation of Korea (NRF) funded by the Ministry of Education (grant number: 2021R1I1A3044565).

Institutional Review Board Statement: Not applicable.

Data Availability Statement: Not applicable.

Conflicts of Interest: The authors declare no conflict of interest.

\section{References}

1. Joshi, R.K.; Carbone, P.; Wang, F.C.; Kravets, V.G.; Su, Y.; Grigorieva, I.V.; Wu, H.A.; Geim, A.K.; Nair, R.R. Precise and Ultrafast Molecular Sieving Through Graphene Oxide Membranes. Science 2014, 343, 752-754. [CrossRef] [PubMed]

2. Karahan, H.E.; Goh, K.; Zhang, C.; Yang, E.; Yıldırım, C.; Chuah, C.Y.; Ahunbay, M.G.; Lee, J.; Tantekin-Ersolmaz, S..B.; Chen, Y.; et al. MXene Materials for Designing Advanced Separation Membranes. Adv. Mater. 2020, 32, 1906697. [CrossRef] [PubMed]

3. Tansel, B. Significance of thermodynamic and physical characteristics on permeation of ions during membrane separation: Hydrated radius, hydration free energy and viscous effects. Sep. Purif. Technol. 2012, 86, 119-126. [CrossRef]

4. Nie, L.; Goh, K.; Wang, Y.; Lee, J.; Huang, Y.; Karahan, H.E.; Zhou, K.; Guiver, M.D.; Bae, T.-H. Realizing small-flake graphene oxide membranes for ultrafast size-dependent organic solvent nanofiltration. Sci. Adv. 2020, 6, eaaz9184. [CrossRef]

5. Lee, J.; Wang, R.; Bae, T.-H. A comprehensive understanding of co-solvent effects on interfacial polymerization: Interaction with trimesoyl chloride. J. Membr. Sci. 2019, 583, 70-80. [CrossRef]

6. Lee, J.; Jang, J.H.; Chae, H.-R.; Lee, S.H.; Lee, C.-H.; Park, P.-K.; Won, Y.-J.; Kim, I.-C. A facile route to enhance the water flux of a thin-film composite reverse osmosis membrane: Incorporating thickness-controlled graphene oxide into a highly porous support layer. J. Mater. Chem. A 2015, 3, 22053-22060. [CrossRef]

7. Lee, J.; Wang, R.; Bae, T.-H. High-performance reverse osmosis membranes fabricated on highly porous microstructured supports. Desalination 2018, 436, 48-55. [CrossRef]

8. Lee, J.; Lim, Y.J. On the Control Strategy to Improve the Salt Rejection of a Thin-Film Composite Reverse Osmosis Membrane. Appl. Sci. 2021, 11, 7619. [CrossRef]

9. Morelos-Gomez, A.; Cruz-Silva, R.; Muramatsu, H.; Ortiz-Medina, J.; Araki, T.; Fukuyo, T.; Tejima, S.; Takeuchi, K.; Hayashi, T.; Terrones, M.; et al. Effective $\mathrm{NaCl}$ and dye rejection of hybrid graphene oxide/graphene layered membranes. Nat. Nanotechnol. 2017, 12, 1083-1088. [CrossRef]

10. Guan, K.; Jia, Y.; Lin, Y.; Wang, S.; Matsuyama, H. Chemically Converted Graphene Nanosheets for the Construction of Ion-Exclusion Nanochannel Membranes. Nano Lett. 2021, 21, 3495-3502. [CrossRef]

11. Cohen-Tanugi, D.; Grossman, J.C. Water Desalination across Nanoporous Graphene. Nano Lett. 2012, 12, 3602-3608. [CrossRef] [PubMed] 
12. Chen, Q.; Yang, X. Pyridinic nitrogen doped nanoporous graphene as desalination membrane: Molecular simulation study. J. Membr. Sci. 2015, 496, 108-117. [CrossRef]

13. Guerrero-Avilés, R.; Orellana, W. Energetics and diffusion of liquid water and hydrated ions through nanopores in graphene: Ab initio molecular dynamics simulation. Phys. Chem. Chem. Phys. 2017, 19, 20551-20558. [CrossRef] [PubMed]

14. Gao, H.; Shi, Q.; Rao, D.; Zhang, Y.; Su, J.; Liu, Y.; Wang, Y.; Deng, K.; Lu, R. Rational design and strain engineering of na-noporous boron nitride nanosheet membranes for water desalination. J. Phys. Chem. C 2017, 121, 22105-22113. [CrossRef]

15. Liu, Y.; Cheng, Z.; Song, M.; Jiang, L.; Fu, G.; Liu, L.; Li, J. Molecular dynamics simulation-directed rational design of nanoporous graphitic carbon nitride membranes for water desalination. J. Membr. Sci. 2021, 620, 118869. [CrossRef]

16. Pathania, Y. Gaganpreet Self-passivated nanoporous phosphorene as a membrane for water desalination. Desalination 2020, 497, 114777. [CrossRef]

17. Li, Z.; Han, Q.; Qiu, Y. Field-enhanced water transport in sub-nanometer graphene nanopores. Desalination 2022, 528, 115610 [CrossRef]

18. Celebi, K.; Buchheim, J.; Wyss, R.M.; Droudian, A.; Gasser, P.; Shorubalko, I.; Kye, J.-I.; Lee, C.; Park, H.G. Ultimate Permeation Across Atomically Thin Porous Graphene. Science 2014, 344, 289-292. [CrossRef]

19. Buchheim, J.; Wyss, R.M.; Shorubalko, I.; Park, H.G. Understanding the interaction between energetic ions and freestanding graphene towards practical 2D perforation. Nanoscale 2016, 8, 8345-8354. [CrossRef]

20. Roy, A.; Shen, J.; Joshi, H.; Song, W.; Tu, Y.-M.; Chowdhury, R.; Ye, R.; Li, N.; Ren, C.; Kumar, M.; et al. Foldamer-based ultrapermeable and highly selective artificial water channels that exclude protons. Nat. Nanotechnol. 2021, 16, 911-917. [CrossRef]

21. Shen, J.; Ye, R.; Zeng, H. Crystal Packing-Guided Construction of Hetero-Oligomeric Peptidic Ensembles as Synthetic 3-in-1 Transporters. Angew. Chem. Int. Ed. 2021, 60, 12924-12930. [CrossRef] [PubMed]

22. Shen, J.; Ye, R.; Romanies, A.; Roy, A.; Chen, F.; Ren, C.; Liu, Z.; Zeng, H. Aquafoldmer-Based Aquaporin-like Synthetic Water Channel. J. Am. Chem. Soc. 2020, 142, 10050-10058. [CrossRef] [PubMed]

23. Lagona, J.; Mukhopadhyay, P.; Chakrabarti, S.; Isaacs, L. The Cucurbit[n]uril Family. Angew. Chem. Int. Ed. 2005, 44, 4844-4870. [CrossRef]

24. Barrow, S.J.; Kasera, S.; Rowland, M.J.; del Barrio, J.; Scherman, O.A. Cucurbituril-Based Molecular Recognition. Chem. Rev. 2015, 115, 12320-12406. [CrossRef] [PubMed]

25. Lee, J.W.; Samal, S.; Selvapalam, N.; Kim, H.-J.; Kim, K. Cucurbituril homologues and derivatives: New opportunities in su-pramolecular chemistry. Acc. Chem. Res. 2003, 36, 621-630. [CrossRef]

26. Baek, K.; Xu, D.; Murray, J.; Kim, S.; Kim, K. Permselective 2D-polymer-based membrane tuneable by host-guest chemistry. Chem. Commun. 2016, 52, 9676-9678. [CrossRef] [PubMed]

27. Cao, X.; Guo, J.; Cai, J.; Liu, M.; Japip, S.; Xing, W.; Sun, S. The encouraging improvement of polyamide nanofiltration membrane by cucurbituril-based host-guest chemistry. AIChE J. 2020, 66, e16879. [CrossRef]

28. Lee, J.; Zhou, F.; Baek, K.; Kim, W.; Su, H.; Kim, K.; Wang, R.; Bae, T.-H. Use of rigid cucurbit[6]uril mediating selective water transport as a potential remedy to improve the permselectivity and durability of reverse osmosis membranes. J. Membr. Sci. 2021, 623, 119017. [CrossRef]

29. Baek, K.; Yun, G.; Kim, Y.; Kim, D.; Hota, R.; Hwang, I.; Xu, D.; Ko, Y.H.; Gu, G.H.; Suh, J.H. Free-standing, single-monomer-thick two-dimensional polymers through covalent self-assembly in solution. J. Am. Chem. Soc. 2013, 135, 6523-6528. [CrossRef]

30. Van der Spoel, D.; Lindahl, E.; Hess, B.; Groenhof, G.; Mark, A.E.; Berendsen, H.J.C. GROMACS: Fast, flexible, and free. J. Comput. Chem. 2005, 26, 1701-1718. [CrossRef]

31. Duan, Y.; Wu, C.; Chowdhury, S.; Lee, M.C.; Xiong, G.; Zhang, W.; Yang, R.; Cieplak, P.; Luo, R.; Lee, T.; et al. A point-charge force field for molecular mechanics simulations of proteins based on condensed-phase quantum mechanical calculations. J. Comput. Chem. 2003, 24, 1999-2012. [CrossRef] [PubMed]

32. Jorgensen, W.L.; Chandrasekhar, J.; Madura, J.D.; Impey, R.W.; Klein, M.L. Comparison of simple potential functions for simulating liquid water. J. Chem. Phys. 1983, 79, 926-935. [CrossRef]

33. Dennington, R.; Keith, T.; Millam, J. GaussView; Version 5; Semichem Inc.: Shawnee Mission, KS, USA, 2009.

34. Kusalik, P.G.; Svishchev, I.M. The Spatial Structure in Liquid Water. Science 1994, 265, 1219-1221. [CrossRef] [PubMed]

35. Jedlovszky, P.; Richardi, J. Comparison of different water models from ambient to supercritical conditions: A Monte Carlo simulation and molecular Ornstein-Zernike study. J. Chem. Phys. 1999, 110, 8019-8031. [CrossRef]

36. Sorenson, J.M.; Hura, G.; Glaeser, R.M.; Head-Gordon, T. What can X-ray scattering tell us about the radial distribution func-tions of water? J. Chem. Phys. 2000, 113, 9149-9161. [CrossRef]

37. Zhao, Y.; Truhlar, D.G. The M06 suite of density functionals for main group thermochemistry, thermochemical kinetics, noncovalent interactions, excited states, and transition elements: Two new functionals and systematic testing of four M06-class functionals and 12 other functionals. Theor. Chem. Acc. 2008, 120, 215-241. [CrossRef]

38. Ditchfield, R.; Hehre, W.J.; Pople, J.A. Self-consistent molecular-orbital methods. Extended Gaussian-type basis for molecularorbital studies of organic molecules. J. Chem. Phys. 1971, 54, 724-728. [CrossRef]

39. Frisch, M.J.; Trucks, G.W.; Schlegel, H.B.; Scuseria, G.E.; Robb, M.A.; Cheeseman, J.R.; Scalmani, G.; Barone, V.; Mennucci, B.; Petersson, G.A.; et al. Gaussian 09; Revision A.1; Gaussian, Inc.: Wallingford, CT, USA, 2009. 